\title{
Using an intraoperative computed tomography scanner with a navigation station for spinal surgery
}

\author{
Kh. Mukhametzhanov ${ }^{1}$, D. Zh. Mukhametzhanov², B. M. Karibaev¹, Sh. A. Bulekbaev³, O. S. Bekarisov', K. K. Kusainova ${ }^{3}$, \\ N. N. Dyusenbaev ${ }^{4}$
}

\begin{abstract}
The authors conducted a retrospective and prospective analysis of the results of 350 operations using the EIC, 390 operations with O arm and 11 operations with $\mathrm{O}$ arm and the Stealth-Station navigation station (Medtronic, USA).

To the 350 patients operated on using the EIC, 1822 screws were implanted, on average 5.2 screws per operation. 117 (6.5\%) screws were implanted incorrectly, of which a permissible or clinically insignificant malposition of the screw was noted in 90 (4.9\%) patients. Incorrectly installed screws remaining in 27 (1.5\%) patients required revision surgery.

To 390 patients operated with $O$ arm, 2477 screws were implanted, on average 6.3 screws during one operation. Incorrectly 33 (1.3\%) screws were implanted, of which 25 screws were acceptable malposition. Invalid malposition of $8(0.3 \%)$ screws was eliminated during the current operation.

Comparing trials of the total number of incorrectly implanted screws during operations using the EIC and $\mathrm{O}$ arm showed that they were more often observed when using the EIC $(p<0.001)$ and there was no unacceptable malposition of the screws when performing the operation under $\mathrm{O}$ arm, since it was diagnosed in time during current operation and eliminated.

A total of 66 screws were implanted in 11 patients operated using $O$ arm and the Stealth-Station navigation station, an average of 6 screws during one operation. Inaccurate implantation of screws was not observed in any patient.

$\mathrm{O}$-arm with the Stealth-Station navigation station is the most modern method of controlling the correctness of spinal operations when anatomical landmarks are partially invisible - with open operations or invisible at all - with minimally invasive surgical interventions in real time.
\end{abstract}

Keywords: intraoperative computed tomography, electron-optical transducer, navigation station, transpedicular fixation

\section{INTRODUCTION}

The modern standard method for the precise installation of pedicle screws is the 2D imaging of an electronic image converter (EIC). However, a downside of this technique is the lack of axial projection information necessary for the proper installation of pedicle screws. Lack of information in axial projection can result in improper installation of screws.

According to figures provided by authors, the frequency of complications of the procedure of percutaneous vertebroplasty (PVP), performed for the treatment of osteoporosis, does not exceed $2 \%$, for the treatment of tumor of the spine - $10 \%(1,2)$.

Inaccurate installation of transpedicular screws could lead to pain, hematomas, infections, bleeding, pseudoaneurysms, lung perforation, ureter, intestines and esophagus, as well as paralysis of the extremities (3-6), damage to nerve roots (6-9), spinal cord infarction (10), neurological disorders (11).

The Intraoperative Cone Beam Computed Tomography (O-arm) and Stealth-Station Navigation Station provide surgical imaging through 2D and 3D scanning to make the right clinical decisions.

The aim of the study was to analyze the results of operations using the image EIC, O-arm and O-arm with the StealthStation navigation station.

\footnotetext{
1 Scientific - Research Institute of Traumatology and Orthopedics, Nur-Sultan, Kazakhstan.

2 National Medical Research Center of Neurosurgery named after N.N. Burdenko, Moscow, Russia.

3 National Center Children's Rehabilitation Corporate Fund "University Medical Center", Nur-Sultan, Kazakhstan

4 JSC « Astana Medical University », Nur-Sultan, Kazakhstan
}

\author{
Correspondence: Kh. Mukhametzhanov \\ Scientific - Research Institute of Traumatology and Orthopedics, Nur-Sultan \\ Kazakhstan
}

Received: 4 Jul 2019, Accepted: 8 Dec 2019

(C) 2019 by the authors; licensee Modestum Ltd., UK. This article is an open access article distributed under the terms and conditions of the Creative Commons Attribution License (http://creativecommons.org/licenses/by/4.0/). 


\section{MATERIALS AND METHODS}

A retrospective and prospective analysis of the results of 350 operations using the EIC, 390 operations with $\mathrm{O}$ arm and 11 operations with $\mathrm{O}$ arm and the navigation station Stealth-Station (Medtronic, USA) was carried out. The study of operations using an EOP included only those patients who underwent control computed tomography (CT) examination of the spine after surgery.

445 (59.2\%) were men and 306 (40.8\%) were female. Most patients were admitted to the clinic in acute $529(70.4 \%)$ and early 86 (11.4\%) periods of injury, $66(8.8 \%)$ in the interim and $70(9.4 \%)$ in the tardive periods.

Injury was received in the home by 447 (59.5\%) patients, 168 (22.4\%) during a road traffic incidents (RTI), 131 (17.4\%) - at work, and $5(0.7 \%)$ - at sports activities. According to the mechanism of trauma, 391 (52.1\%) patients were injured in a fall from a high height, 168 (22.4\%) - in RTI, 147 (19.6\%) - in a fall from a height of the tall, 38 (5\%) - when the load fell on the back and other mechanism of injury was noted in 7 (0.9\%) victims.

After a clinical and neurological examination, all patients underwent radiography, CT, 689 (91.7\%) X-ray densitometry, 259 (34.5\%) - electroneuromyography, 58 (7.7\%) - magnetic resonance imaging, 216 (28.8\%) according to indications, myelography before, during or after surgery, 130 (17.4\%) - venospondylography before PVP.

All spinal fractures were unstable, fractures of type A2 and A3 (84.7\%) in AO predominated, then of type B2 (8.7\%) and type $C$ (6.6\%). Fractures of the lumbar spine were observed in 408 (54.4\%) sufferers, chest - in 176 (23.4\%), two departments - in 116 (15.4\%) and two-level fractures - in 51 (6.8\%) patients. Complicated spinal fractures were noted in 184 (24.5\%), type $A$ injuries in $2 \%, B$ in $10.2 \%, C$ in $57.2 \%$ and $D$ in $30.6 \%$ of the injured. Combined injuries were detected in 297 (39.5\%) patients, which in 96 (12.8\%) were accompanied by traumatic shock.

Internal transpedicular fixation (ITF) was used in the form of monosegmental, bisegmental with implantation from 4 to 6 screws, three-segmented from 4 to 8 screws, multisegmented from 6 to 14 screws, as well as pediculo-laminar fixation using laminar hooks along with screws. For ITF, the systems NITEK (Novosibirsk), Medbiotech (Belarus), ChM (Poland), XIA 2 (Stryker) and Medtronic (USA) were used.

According to indications, ITF was supplemented by interbody fusion in 107 (14.2\%), transpedicular vertebral body plasty (TPVBP) with porous titanium nickel granules in 295 (39.3\%), and PVP in 74 (9.9\%).

45 (6\%) patients underwent percutaenous ITF (PITF), 27 (3.6\%) patients underwent percutaenous TPVBP (PTPVBP), and 7 (0.9\%) patients underwent PVP. Sixtant (Medtronic) and Mantis (Stryker) designs, as well as ChM (Poland), Medtronic (USA), XIA 2 (Stryker, USA), were used for PVTF.

Pearson's chi-square test was used for statistical evaluation. A value of $P<0.05$ was taken as statistically significant.

\section{RESULTS AND DISCUSSION}

The patient is laid on an X-ray transparent operating table on his back, intubated, then turned over onto his stomach, under anesthesia for uncomplicated spinal fractures and the integrity of the posterior support complex, the spinal column is reclaimed by traction by the legs and holding the patient by the shoulder girdle, rollers are placed under the chest and pelvis. The operational field is marked and 2D control EIC are taken by manually positioning the image intensifier tube. The EIC intensifier rolls back from the operating table, the operating field is processed and trimmed, access is made, markers are installed at the sites of the implanted screw implantation. The emitter and the sensing device of the EIC are covered with sterile sheets, 2D pictures are taken. Focusing on the installed markers and 2D images, they gradually make pin channels in the roots of the arches, first with an awl, then with a sword and implant transpedicular screws. In the case of image intensifier tubes in connection with manual positioning, it is often necessary to take intermediate images in order to photograph the previous surgical field. After mounting the structure, final pictures are taken.

To the 350 patients operated on using EIC, 1822 screws were implanted, on average 5.2 screws per operation. 117 (6.5\%) screws were implanted incorrectly, of which a permissible or clinically insignificant malposition of the screw was noted in $90(4.9 \%)$ patients. Incorrectly installed screws remaining in $27(1.5 \%)$ patients required revision surgery (Figure 1).

Clinical example 1. Patient S. 22 years. Diagnosis: "Concomitant injury, closed compression-comminuted uncomplicated penetrating unstable fracture of the Th12 vertebral body, fracture of the spinous and articular processes of Th11-Th12 vertebrae of grade 3, fracture of the spinous processes and arches of Th11-12 vertebrae (A2, B2 by AO), condition after WTF Th10-L1 vertebrae by the NITEC system (09/07/2007). Closed craniocerebral injury. Brain of the concussion". 
$\mathbf{A}$
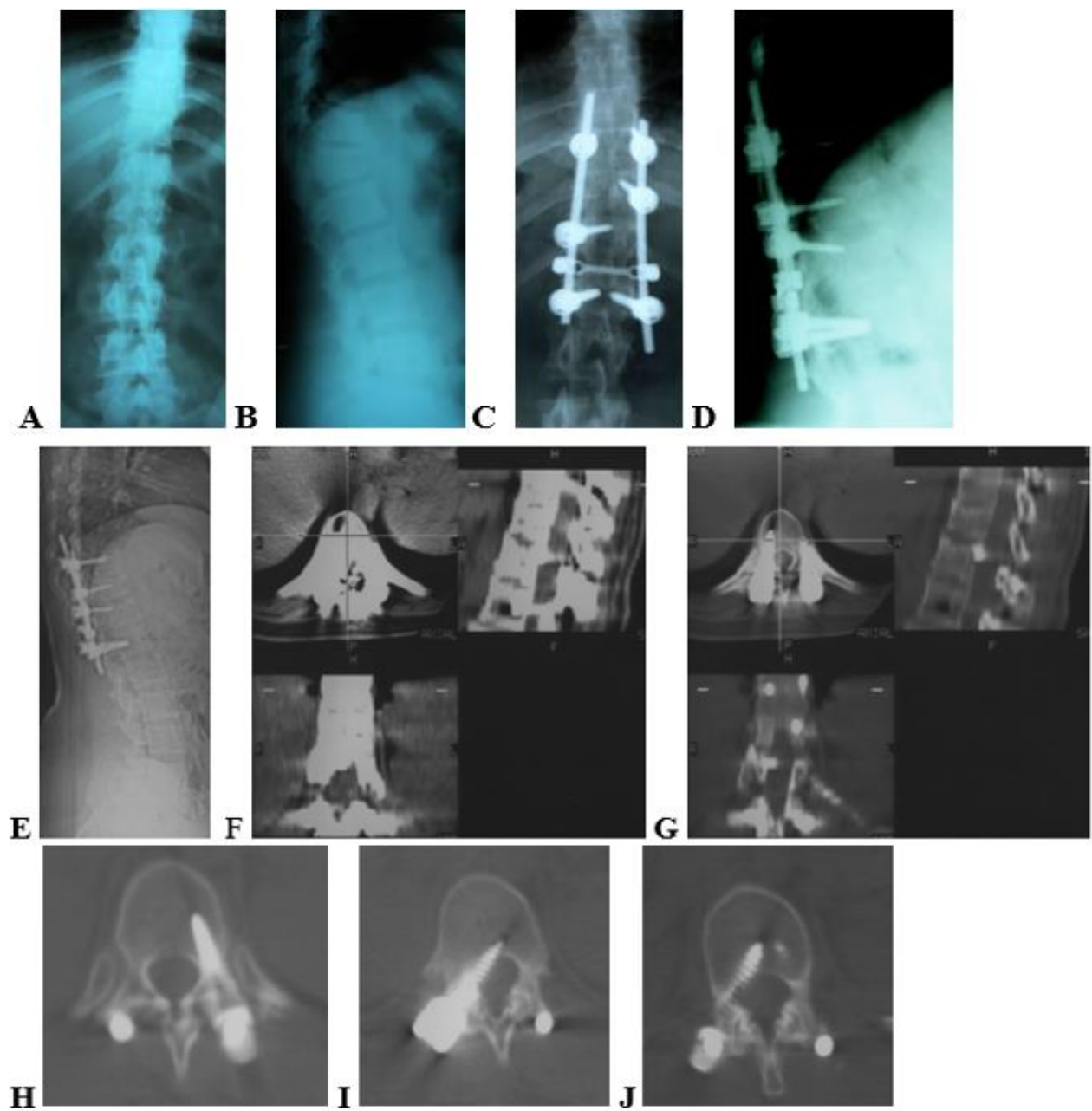

$\mathbf{K}$

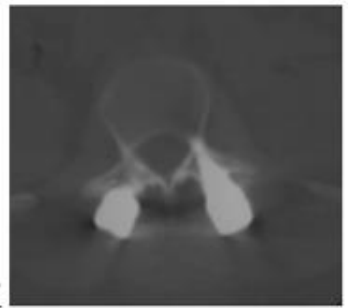

Figure 1: $A, B$ - radiographs before surgery; $C, D$ - radiographs after surgery; $E, F, G, H, I, J, K-C T$ topogram and $C T$ after surgery - incorrectly installed screw

Certain difficulties exist during implantation of transpedicular screws under EIC during post-traumatic spinal deformities, after the operations performed earlier (Figure 2).

Clinical example 2. Patient K., 33 years old. Diagnosis: "After-effectiveness of a closed spinal cord injury, bruise and spinal cord compression (2003), improperly consolidated compression-comminuted fracture of the L2 vertebral body (C2 by AO), decompressive laminectomy L2, posterior spinal fusion with metal plates (06/26/03), removal of metal plates $(07 / 09 / 04)$,

VTF L1-L3 vertebrae (06/28/07); remounting the ITF with the installation of additional screws, ventral interbody fusion with porous titanium nickelide (02.17.2010). Lower flaccid paraparesis, dysfunction of the pelvic organs." 

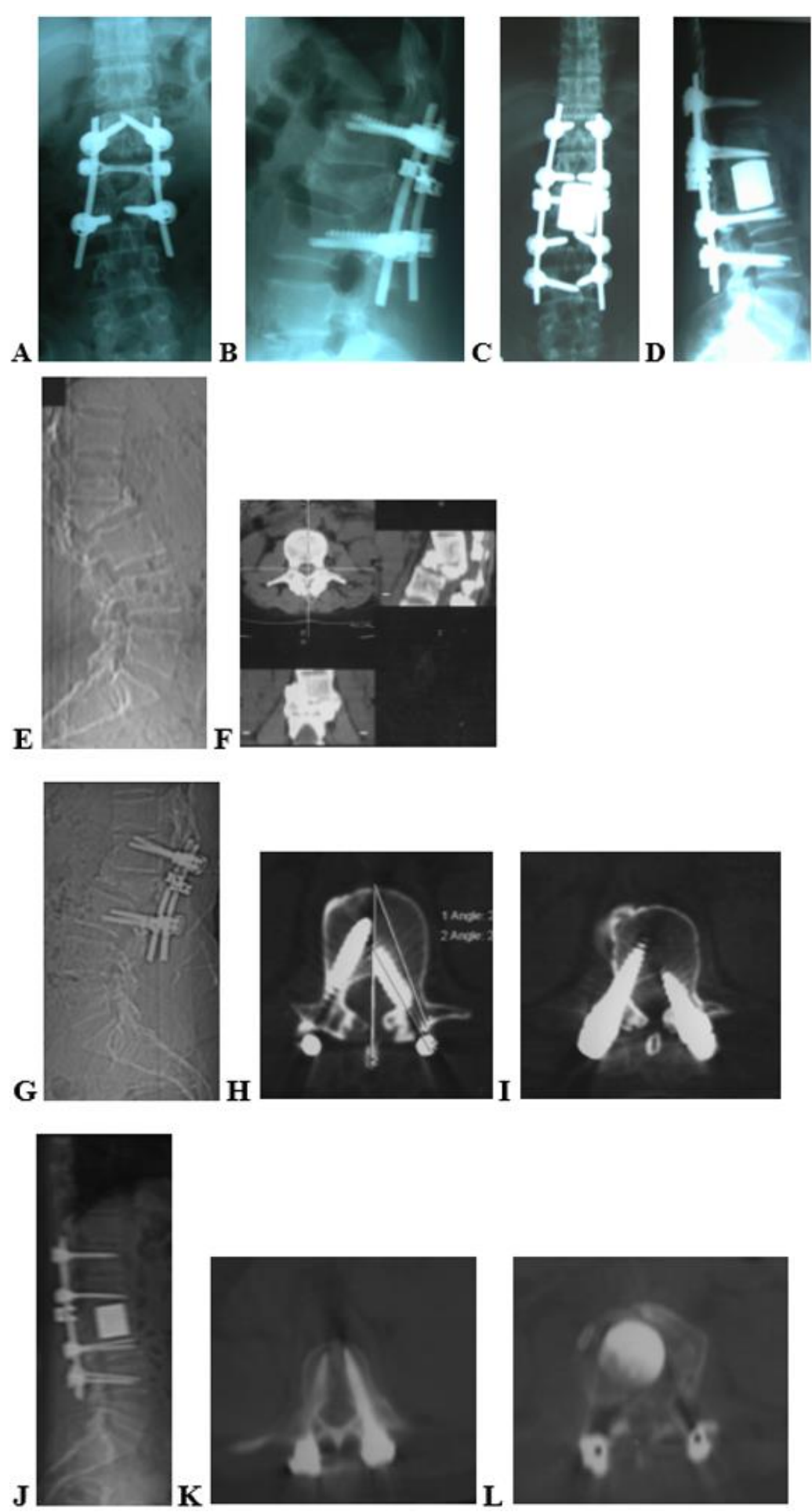

Figure 2: $A, B$ - radiographs after 3 operations; $C, D$ - radiographs after 4 operations; $E, F-C T$ topogram and $3 D$ images after 2 operations - kyphotic spinal deformity; G, H, I, - CT after 3 operations - corrected kyphotic deformation, malposition of screws; J, K, L, M,N - CT after 4 operations of ITF remounting and ventral spinal fusion - topogram and axial sections screws are located exactly in the roots of the arches and in the projection of the body of the resected vertebra is a cage made of porous titanium nickelide

According to the literature, there are certain disadvantages when using an image intensifier tube without navigation: the accuracy level of introducing transpedicular screws ranges from $72 \%$ to $92 \%$ (12-16). When using only the X-ray image intensifier tube system without navigation during the installation of metal structures, control is carried out only due to fluoroscopy. At the same time, patients and surgeons are exposed to relatively high doses of radiation $(17,18)$. When using systems such as an image intensifier tube, a lot of time is spent positioning the fluoroscope during repeated studies, it is impossible to ensure perfect sterility of the surgical aid, sterility is violated, there is a risk of wound infection 
A
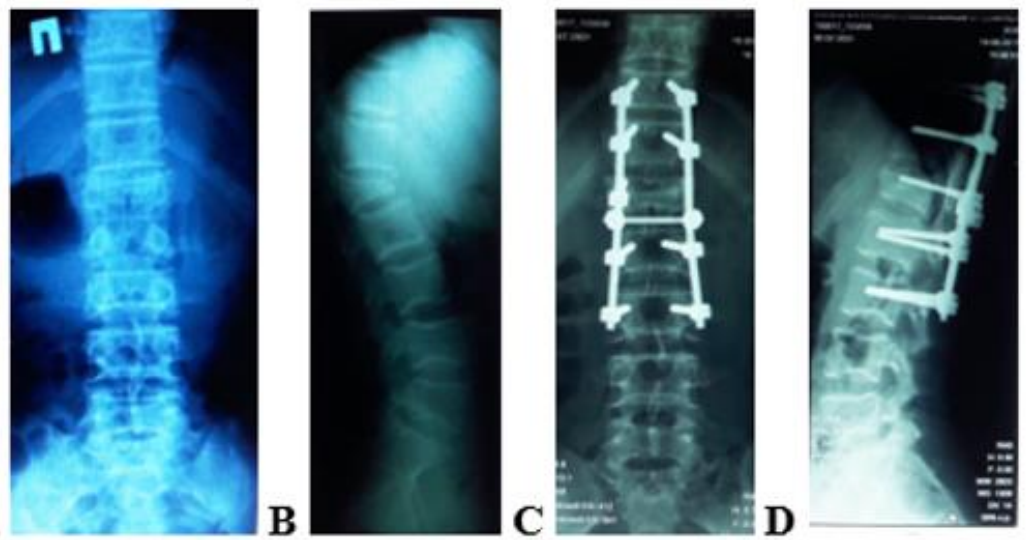

Figure 3: $A, B$ - radiographs before surgery; $C, D$ - radiographs after surgery; $C T$ before surgery: $E, F$ - frontal and sagital reconstruction, $G, H-3 D$ reconstruction before surgery; $\mathbf{O}$ arm images during operation: $I, I-2 D$ images of marker installation; $K, L,-3 D$ reconstruction; $M, N, O, P, Q, R, S$ - control of the location of each marker on the axial, frontal and sagittal section. $T$ - axial reconstruction of the location of all markers. Focusing on the location of the markers in the obtained images of $O$ arm in 3 projections, the direction of insertion of transpedicular screws is specified. After implantation of the screws, 2D and 3D images are taken; on 3D images of $O$ arm, the accuracy of each screw installation individually is controlled (Fig. 4)

(19) and the incidence of infections reaches $4 \%$ (20). Intraoperative fluoroscopy allows you to get information about the position of the screws only within certain limits, not allowing you to control the perforation of the wall of the spinal canal. If the wrong position of the transpedicular screws is not detected at the end of the initial intervention, a second operation may be required to correct their position (21). A study of the correctness of the installation of transpedicular screws during thoracolumbar operations showed that the frequency of revision operations due to improperly installed screws is $1 \%$ (22). The greatest number of incorrect position of the screws is observed during revision operations, since the risk of neurological disorders associated with spinal fusion is $41 \%$ higher than during primary operations on the spine (11).

$\mathrm{O}$-arm is a robotic mobile system and can easily navigate the operating room. Its "O" shape allows the detector to move freely around the patient's body for 3600, both for obtaining 2D images in the required position and for obtaining $3 \mathrm{D}$ images. Henry telescopic system. This allows you to organize lateral access to the patient and install the system near the operating table and roll it away from the table during surgery, which greatly facilitates the use of the system compared to closed systems.

Henry can be positioned in any direction using special buttons. All henry movements and receiver-emitter systems are fully automated. A special command panel allows the operator to accurately and quickly set the henry in the right position. Using the O-arm system, you can save the current position of the henry, the detector with the emitter, as well as the exposure parameters. Up to four combinations of settings can be stored at one time. During the operation, the surgeon can go to any of the saved positions by pressing one button, thereby saving time on positioning and searching for the desired position.

To 390 patients operated with $\mathrm{O}$ arm, 2477 screws were implanted, on average 6.3 screws during one operation. Incorrectly 33 (1.3\%) screws were implanted, of which 25 screws were acceptable malposition. Invalid malposition of 8 (0.3\%) screws was eliminated during the current operation.

Laying the patient on the operating table as during surgery under the image intensifier. After marking the surgical field using $\mathrm{O}$-arm, 2D pictures are taken. The operating field is being processed. Henry $\mathrm{O}$-arm is draped with a sterile cover. When closed, Henry can remain sterile throughout the operation. The system is relegated to a previously saved parking position, giving the surgeon access to the surgical field.

Operational access is carried out, markers are installed in the roots of the arches, 3D images are taken and the correct position of each marker individually is controlled (Figure 3). 


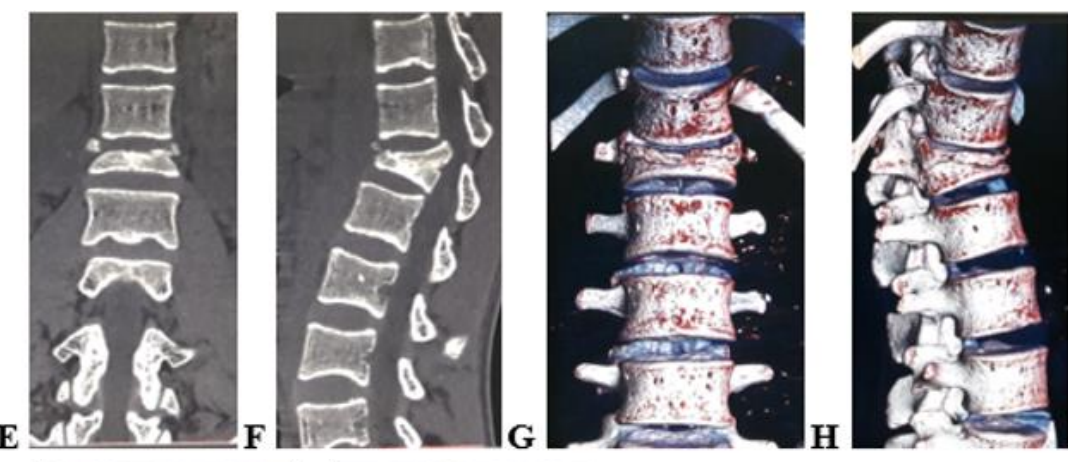

I
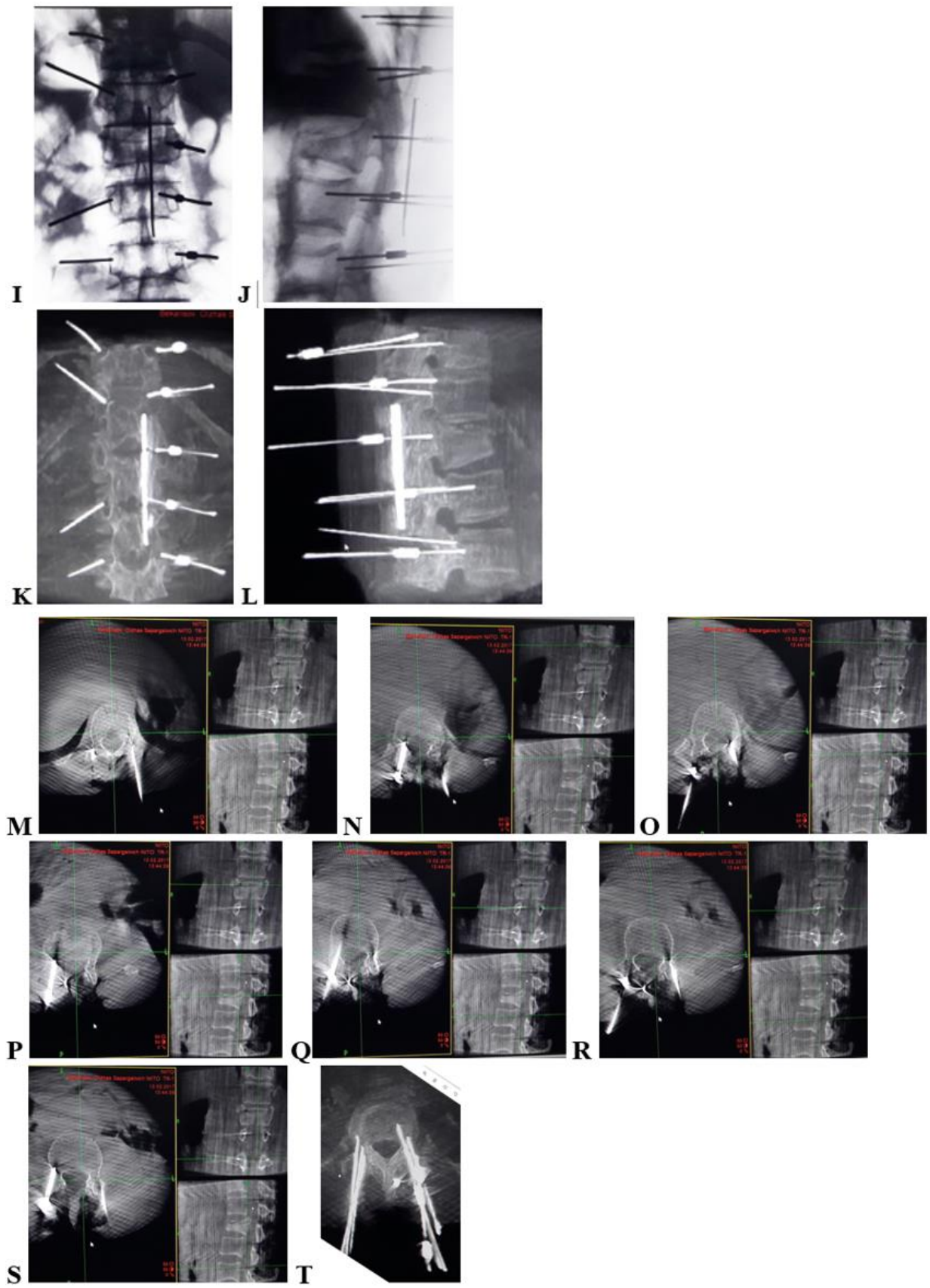

Figure 3 (continued): $A, B$ - radiographs before surgery; $C, D$ - radiographs after surgery; CT before surgery: $E, F$ - frontal and sagital reconstruction, $G, H-3 D$ reconstruction before surgery; $O$ arm images during operation: $I, J-2 D$ images of marker installation; $K, L,-3 D$ reconstruction; $M, N, O, P, Q, R, S$ - control of the location of each marker on the axial, frontal and sagittal section. $T$ - axial reconstruction of the location of all markers. Focusing on the location of the markers in the obtained images of $O$ arm in 3 projections, the direction of insertion of transpedicular screws is specified. After implantation of the screws, 2D and 3D images are taken; on 3D images of $O$ arm, the accuracy of each screw installation individually is controlled (Figure 4) 

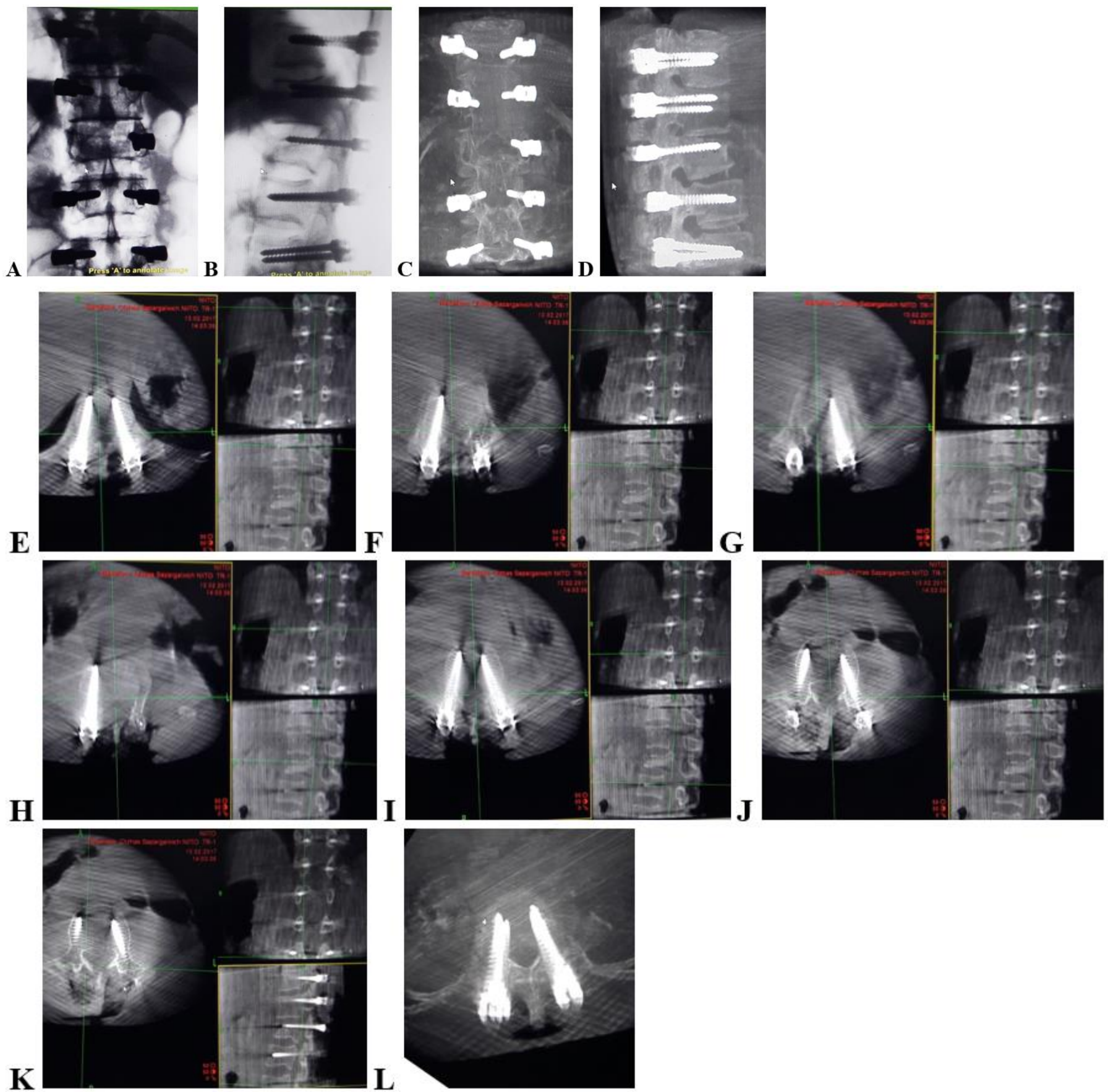

Figure 4: $A, B,-2 D$ images of $O$ arm; $C, D-3 D$ images of $O$ arm; $E, F, G, H, I, K, L$ - control the accuracy of implantation of each screw in the images in axial, frontal and sagittal projections; $H$ - accuracy of implantation of all screws for reconstruction in axial projection

Clinical example 3. Patient D. 16 years old Diagnosis: "Closed unstable complicated compression-comminuted penetrating fracture of the $L 2$ vertebral body of grade 3 with $1 / 2$ spinal stenosis, fracture of the $L 2$ vertebral arch, posttraumatic kyphotic deformity of the thoracolumbar spine (A2, B2 according to AO), contusion of the cone of the spinal cord, mild lower paraparesis, impaired function of the pelvic organs. Condition after ITF of Th11-Th12-L1-L2-L3 bodies of the vertebrae by the Medtronic system (02.13.17). "

Comparative studies of the total number of incorrectly implanted screws during operations using the EIC and O arm showed that they were more often observed when using the EIC $(p<0.001)$ and there was no unacceptable malposition of the screws when performing the operation under $\mathrm{O}$ arm, since it was diagnosed in time during current operation and eliminated.

66 patients were implanted in 11 patients operated using $O$ arm and the Stealth-Station navigation station, an average of 6 screws during one operation. Inaccurate implantation of screws was not observed in any patient. 
$\mathbf{A}$
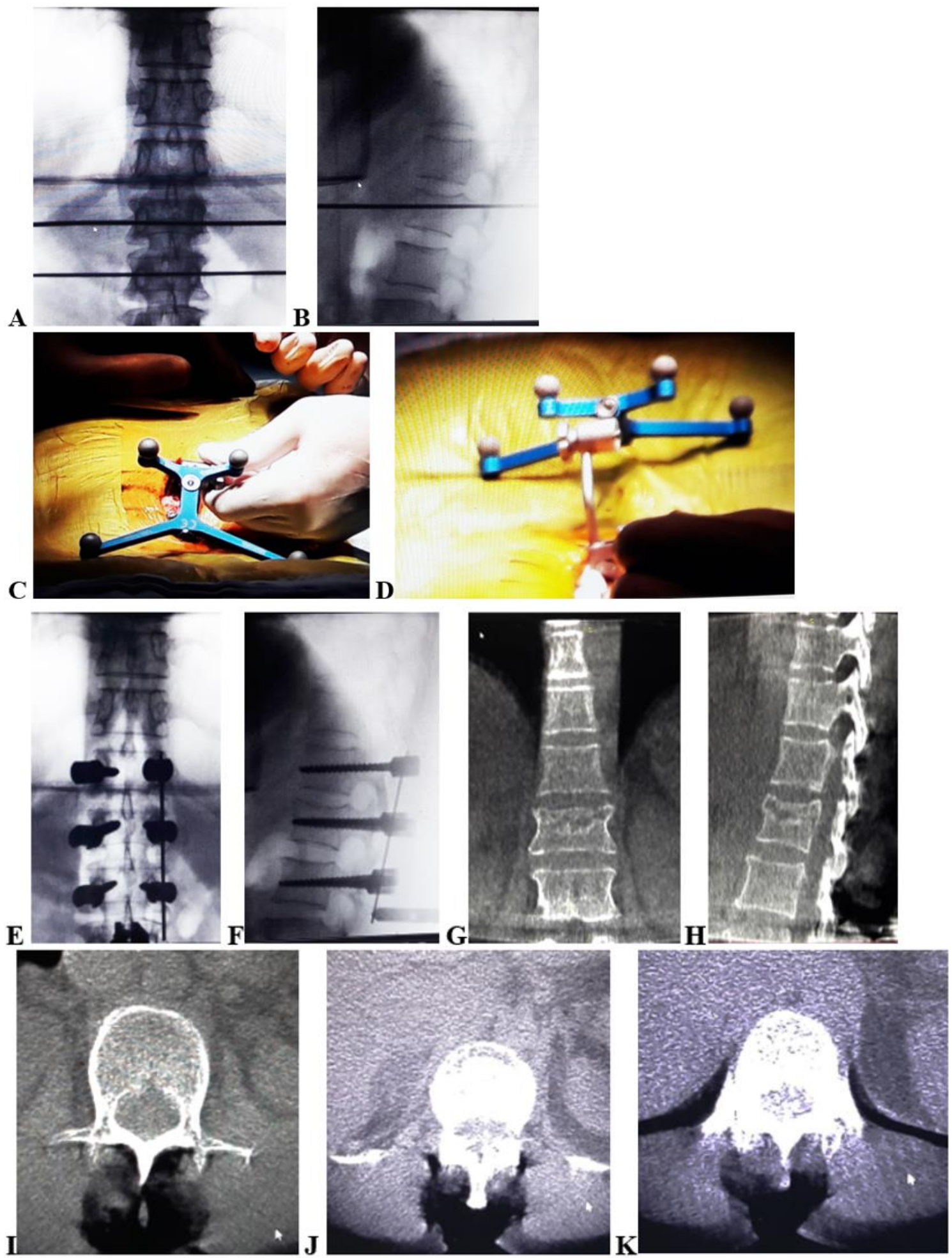

Figure 5: $A, B,-2 D$ images of $O$ arm; $C, D-3 D$ images of $O$ arm; $E, F, G, H, I, K, L$ - control the accuracy of implantation of each screw in the images in axial, frontal and sagittal projections; $H$ - accuracy of implantation of all screws for reconstruction in axial projection

In operations using $\mathrm{O}$ arm and the Stealth-Station navigation station, the algorithm for visualizing the stages of the operation is somewhat different than when using only $\mathrm{O}$ arm. After carrying out all the stages of laying the patient on the operating table (as with the application of the image intensifier tube and in isolation $\mathrm{O}$ arm), marking the surgical field, 2D images are performed (Figure $\mathbf{5}$ A, B). After ensuring operational access, a reference frame is installed (Figure $\mathbf{5} \mathbf{C}, \mathbf{D}$ ), 2D (Figure $\mathbf{5} \mathbf{E}, \mathbf{F}$ ) and 3D (Figure $\mathbf{5} \mathbf{G}, \mathbf{H}, \mathbf{J}, \mathbf{K}, \mathbf{L}$ ) pictures are taken. 3D images are uploaded to the navigation station (Figure $\mathbf{5} \mathbf{M}$ ), identification of the tools (awl, sword, wrench for screws) is carried out, data on the sizes of implanted screws (diameter and length) are entered. 


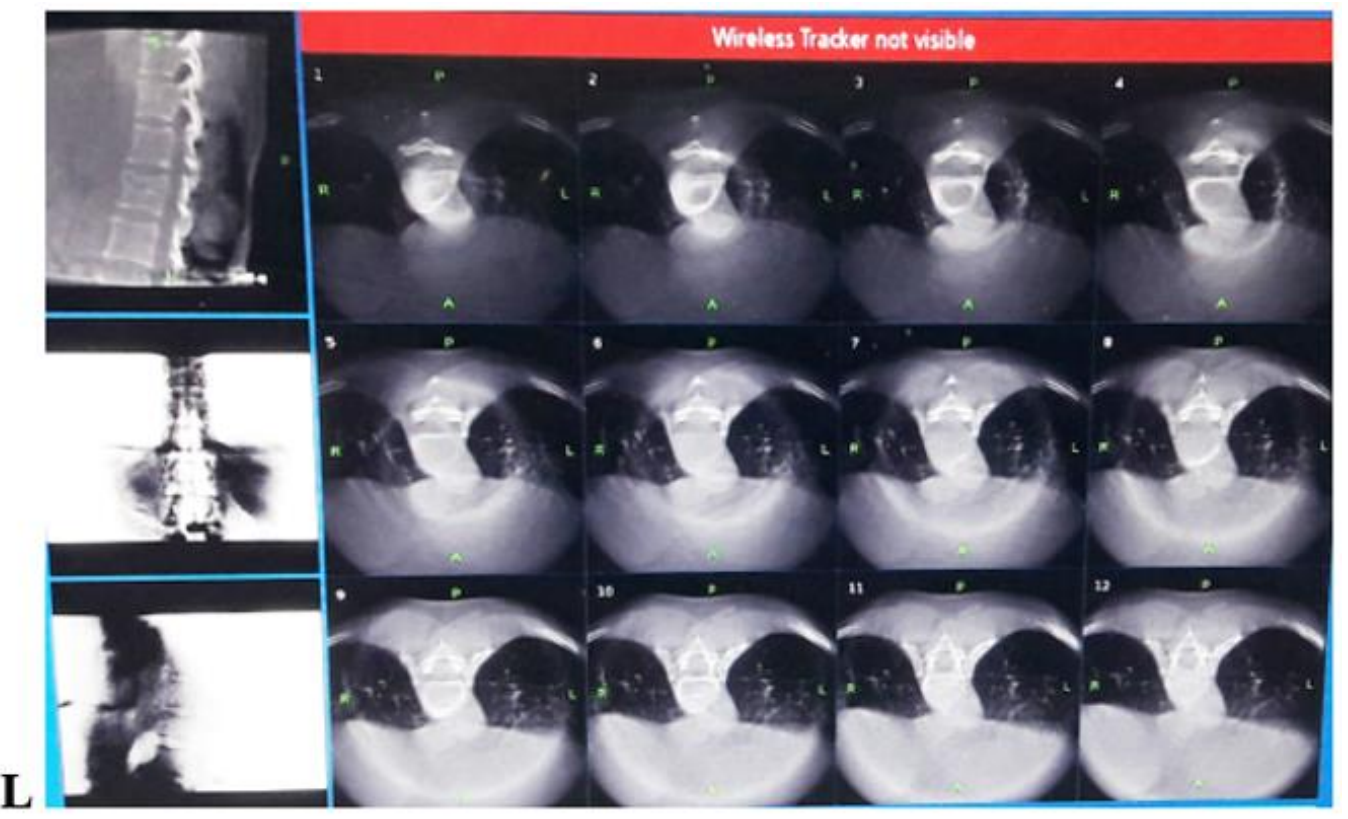

Figure 5 (continued): $A, B,-2 D$ images of $O$ arm; $C, D-3 D$ images of $O$ arm; $E, F, G, H, I, K, L$ - control the accuracy of implantation of each screw in the images in axial, frontal and sagittal projections; $H$-accuracy of implantation of all screws for reconstruction in axial projection

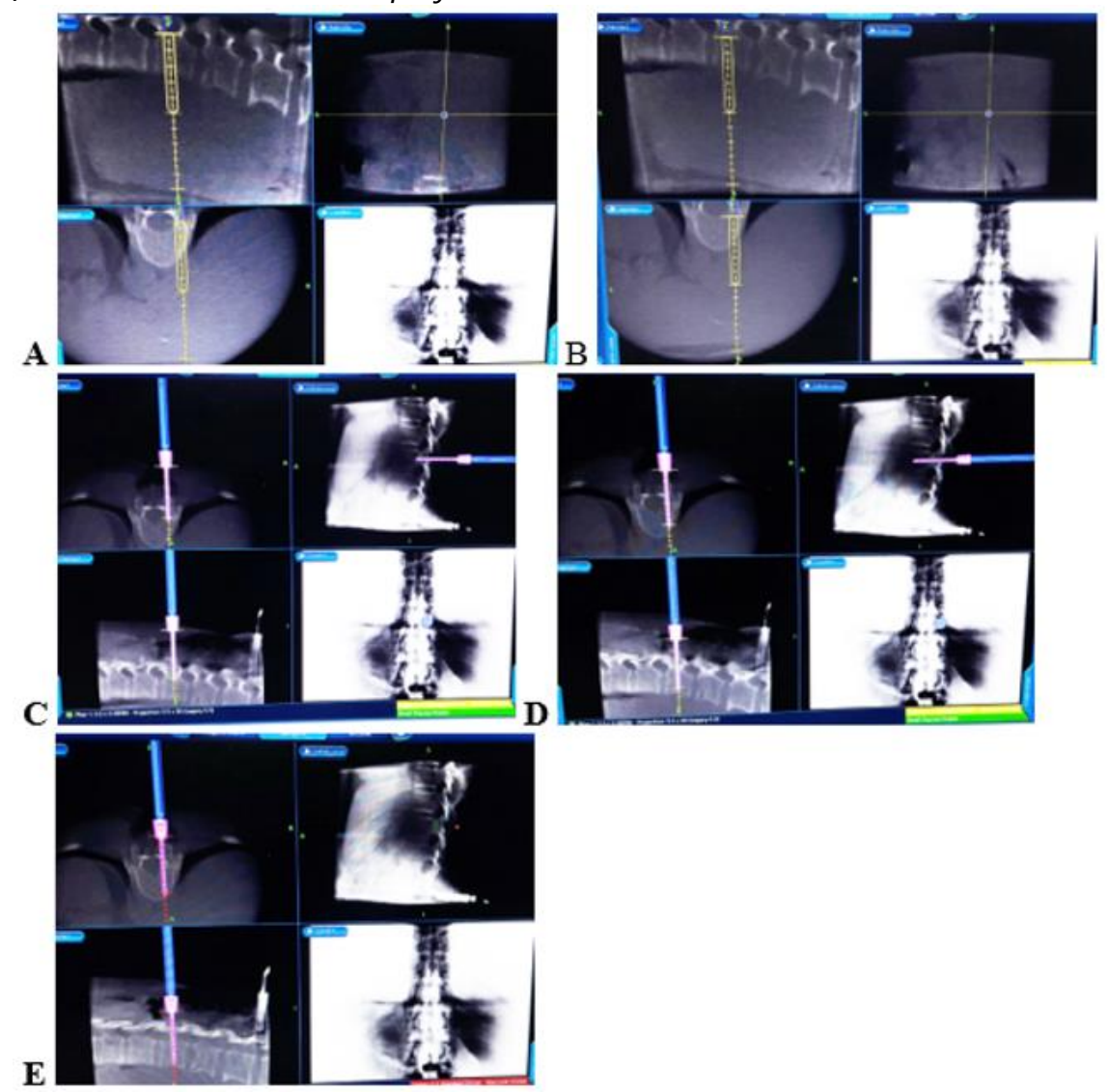

Figure 6: $A$ - channel pin formation with an awl in the root of the arch of the damaged vertebra, $B$ - introduction of a sword outside the arch of the damaged vertebra into the body, $C, D, E$, -introduction of a screw through the arch of the damaged vertebra under visual control; $F$ - channel pin formation with an awl in the root of the arch of the underlying vertebra, $\mathrm{G}$ - introduction of a sword outside the root of the arch of the underlying vertebra into the body; $\mathrm{H}$ - the formation of the channel pin with an awl in the root of the arch

Using the navigation station, the main stages of the operation are carried out: preparation of the pin channels with an awl (Figure 6 A) and a sword (Figure 6 B) for implantation of transpedicular screws, implantation of screws (Figure $\mathbf{6}$ C, D, E). After that, control 3D images of $\mathrm{O}$ arm are made (Figure 7 A, B, C, D, E, F). When confirming the 


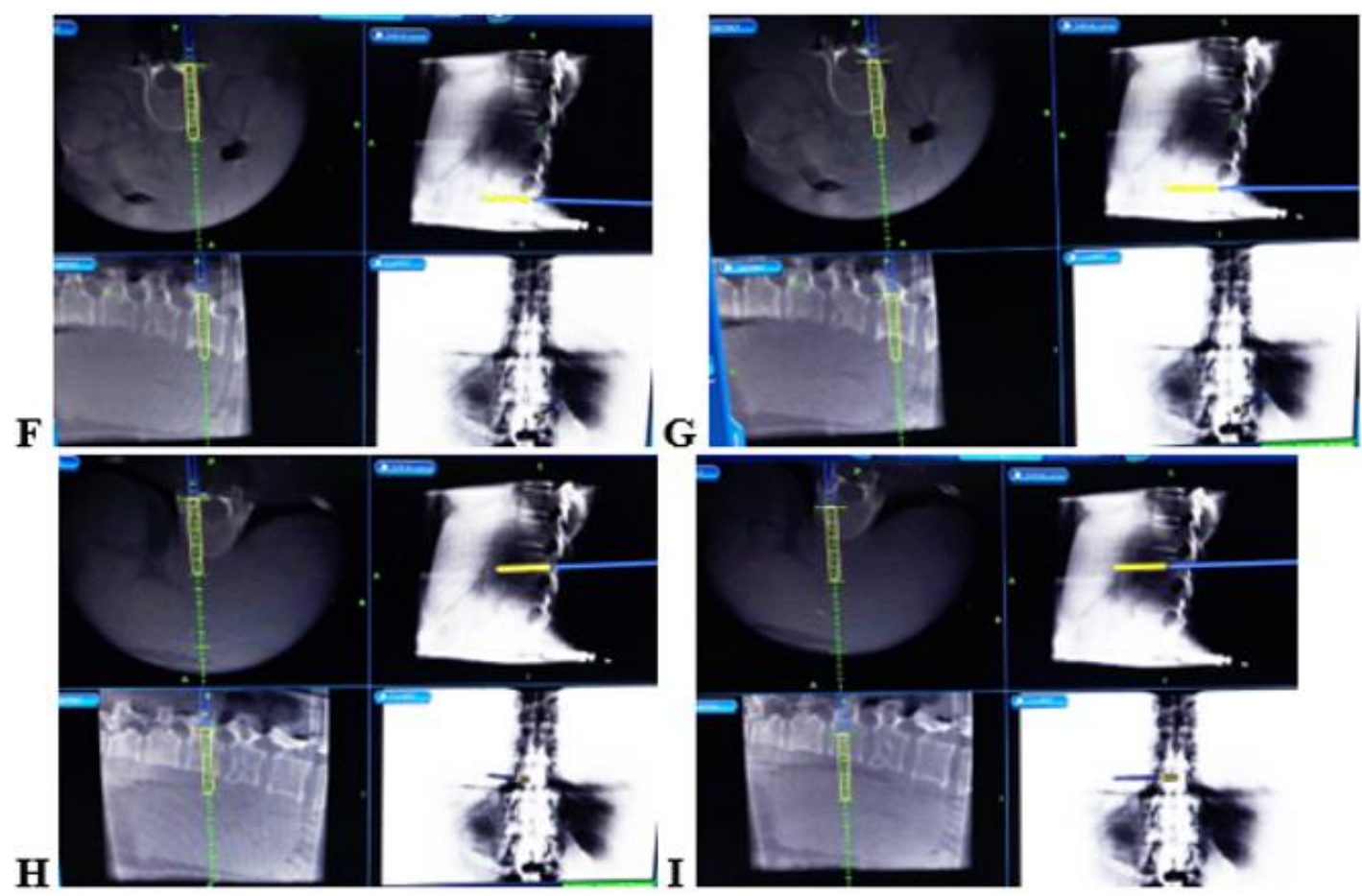

Figure 6 (continued): $A$ - channel pin formation with an awl in the root of the arch of the damaged vertebra, $B$ introduction of a sword outside the arch of the damaged vertebra into the body, $C, D, E$, - introduction of a screw through the arch of the damaged vertebra under visual control; $F$ - channel pin formation with an awl in the root of the arch of the underlying vertebra, $G$ - introduction of a sword outside the root of the arch of the underlying vertebra into the body; $H$ the formation of the channel pin with an awl in the root of the arch
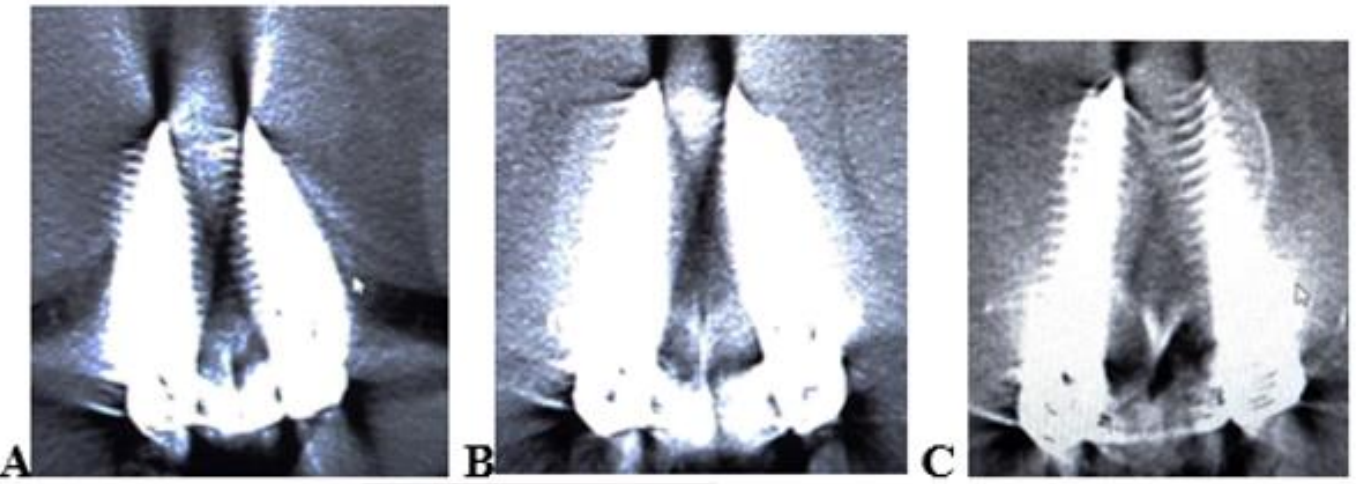

Figure 7: $O$ arm 3D images - $A, B, C$ - axial sections, screws are implanted correctly; $D$ - coronary section, $E, F$ - sagittal sections. $O$ arm 2D images $G, H$-direct and lateral projections; $O$ arm 3D images - I coronary projection, J, $K$ - left and right sagital projection; $L$-the middle section of the sagittal projection and the $M$ - axial section are granules of porous titanium nickelide in the body of the damaged vertebra

accuracy of the installation of the screws, the rods of the transpedicular system are mounted. The final 2D (Figure $\mathbf{7} \mathbf{H}, \mathbf{I}$ ) and 3D images (Figure $\mathbf{7} \mathbf{J}, \mathbf{K}, \mathbf{L}, \mathbf{M}, \mathbf{N}$ ) are performed.

Clinical example 4. Patient O. 53 years old. Diagnosis: "closed compression uncomplicated unstable fracture of the L1 vertebral body of the 2 nd degree, fracture of the spinous process of the Th12 vertebra ( $\mathrm{A} 2, \mathrm{~B} 2$ according to $\mathrm{AO}$ ). The state of vertebral bodies of Th12-L1-L2 vertebrae after the VTF design of the second generation ChM with plastic of the vertebral body L1 by TiNi granules on the left using the O-arm and navigation station (09/18/2019) "(Figure 5, 6, 7).

O-arm easily adapts with the Stealth-Station navigation company Medtronic (USA). Navigation Stealth-Station is the most promising, combining the automatic acquisition of scans with $\mathrm{O}$-arm during surgery and displaying them on the screen to provide navigation tools when installing transpedicular screws. Surgical navigation technology allows the surgeon to navigate the patient's anatomy in real time.

Direct comparison with the classical method of installing transpedicular screws, the O-arm and Stealth-Station systems significantly increase the accuracy of installing transpedicular systems (23-25), which is confirmed by a statistically significant reduction in the number of pathological electromyographic responses (23), and reduces the 
D
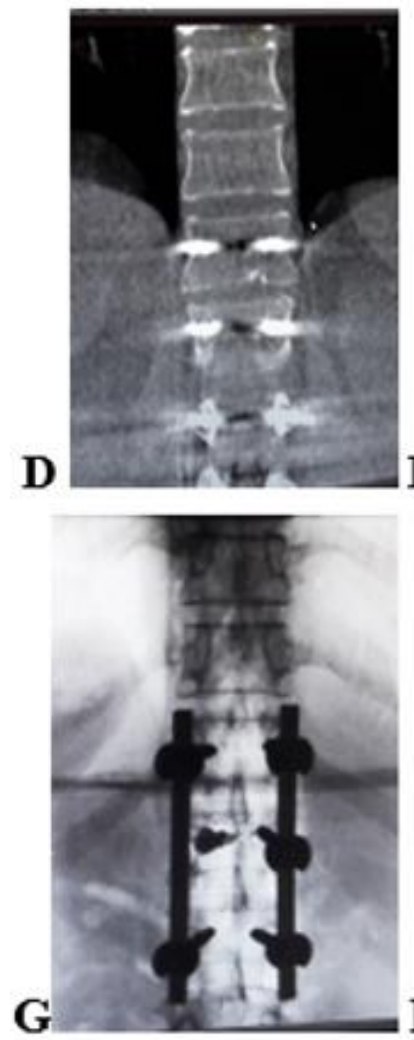

$\mathbf{E}$
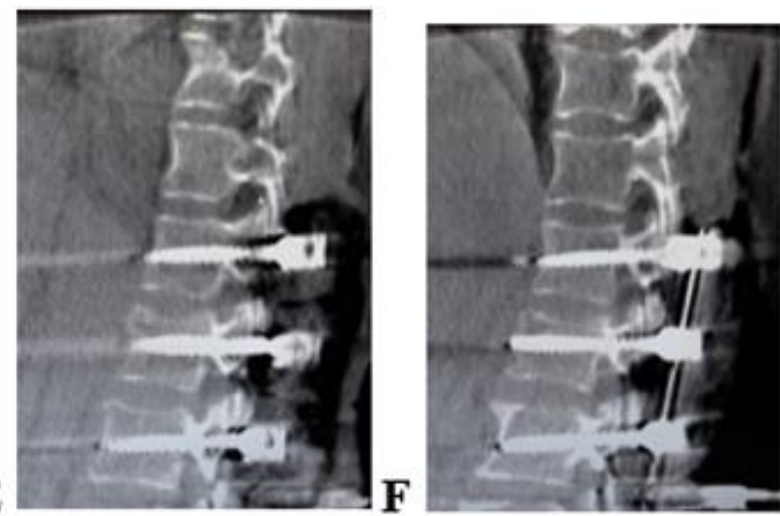

H

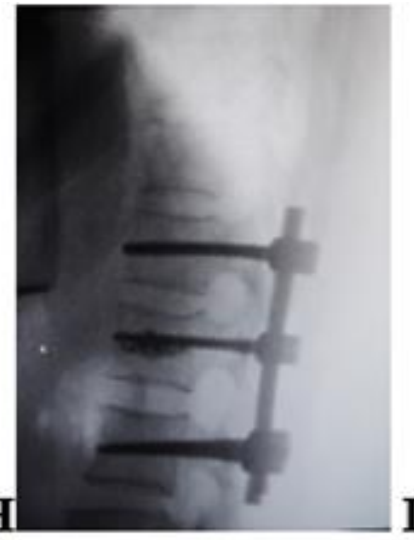

I
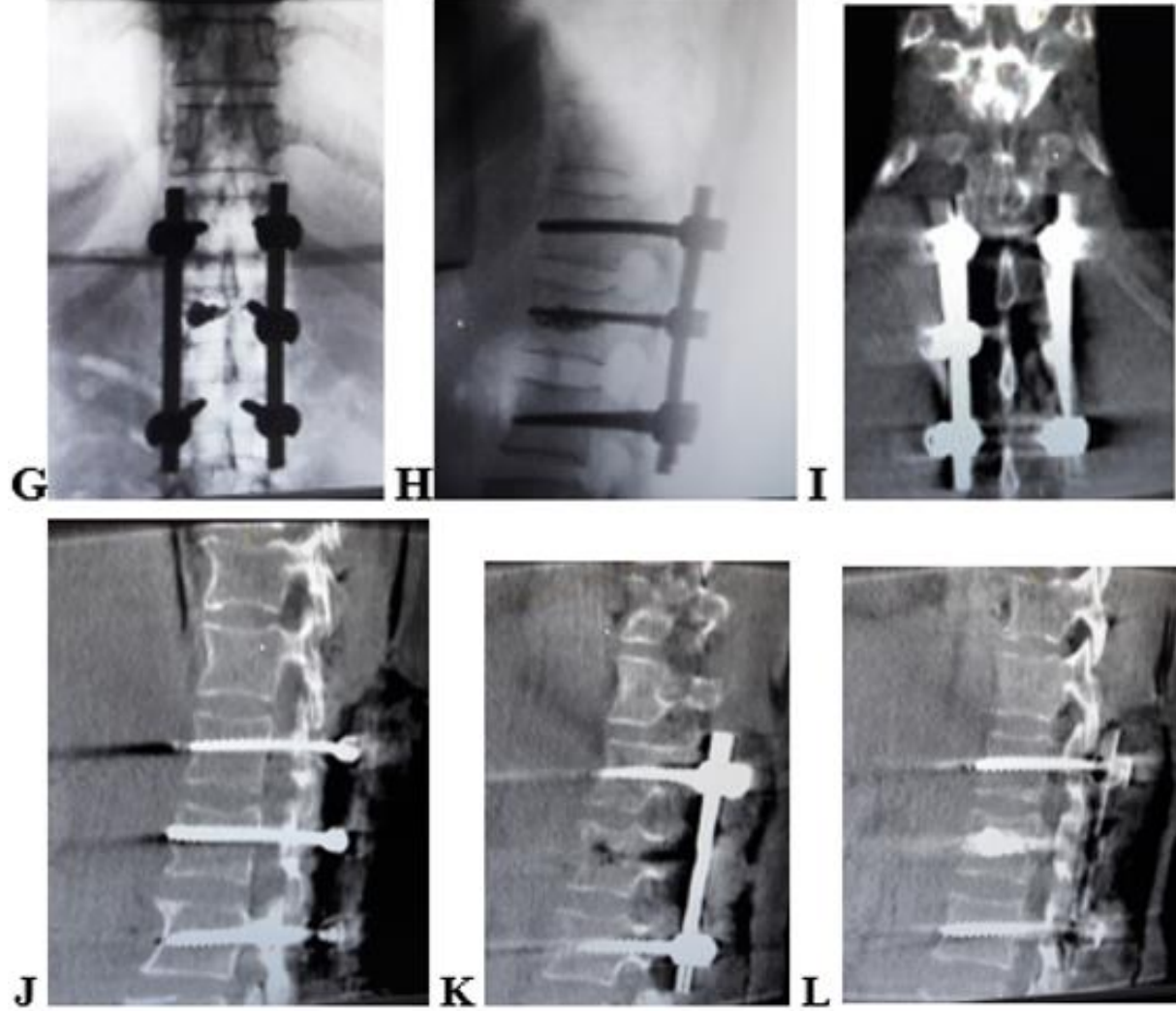

$\mathbf{K}$
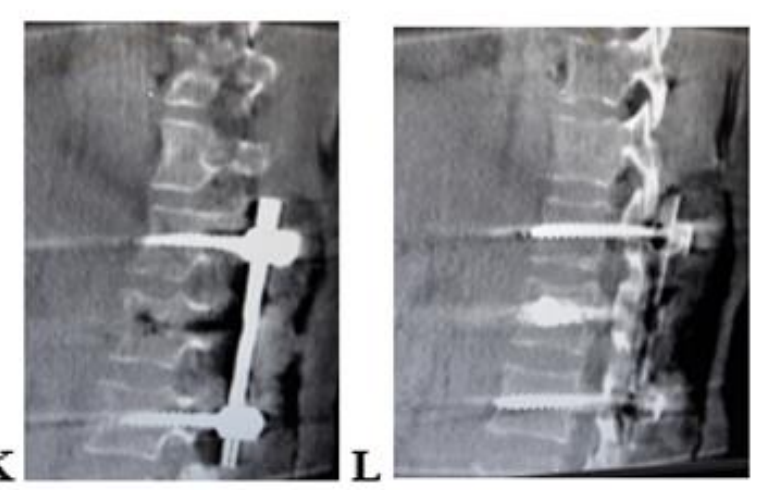

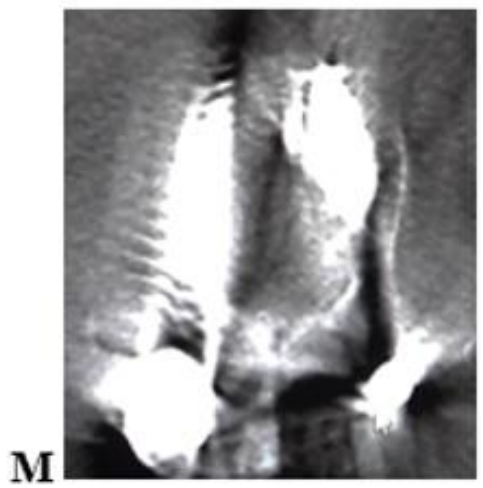

Figure 7 (continued): $\mathbf{O}$ arm 3D images - $A, B, C$ - axial sections, screws are implanted correctly; $D$ - coronary section, $E$, $F$ - sagittal sections. $\mathbf{O}$ arm 2D images $G, H$ - direct and lateral projections; $\boldsymbol{O}$ arm $3 \boldsymbol{D}$ images - I coronary projection, J, $K$ - left and right sagital projection; $L$-the middle section of the sagittal projection and the $M$ - axial section are granules of porous titanium nickelide in the body of the damaged vertebra

radiation dose for the surgeon and patient (24-26), and also provide intraoperative control of improperly set screws (2427). In an indirect comparison, the results of operations using the $\mathrm{O}$-arm and Stealth-Station systems show a higher level of accuracy of installation of transpedicular screws $(95-100 \%)(24,26)$ than the level of accuracy of installation using the classical methodology (84-95\%) (28-32).

The O-arm imaging system and the Stealth-Station navigation station help the surgeon direct the screw according to the patient's anatomical features to bypass the hidden nerves and blood vessels and avoid damage. The O-arm system and the Stealth-Station navigation station provide intraoperative control over the correct installation of screws (24-27).

Performing open operations on the spine, anatomical landmarks for introducing screws are partially visible - the arches of the vertebrae, articular and transverse processes. In transdermal, minimally invasive operations, anatomical landmarks are not visible at all. We performed percutaneous operations for 45 patients: all patients underwent TITF, 27 of them were supplemented with PTPVBP and 7 - PVP. All transdermal operations were performed using O-arm and Oarm with the Stealth-Station navigation station. 
A
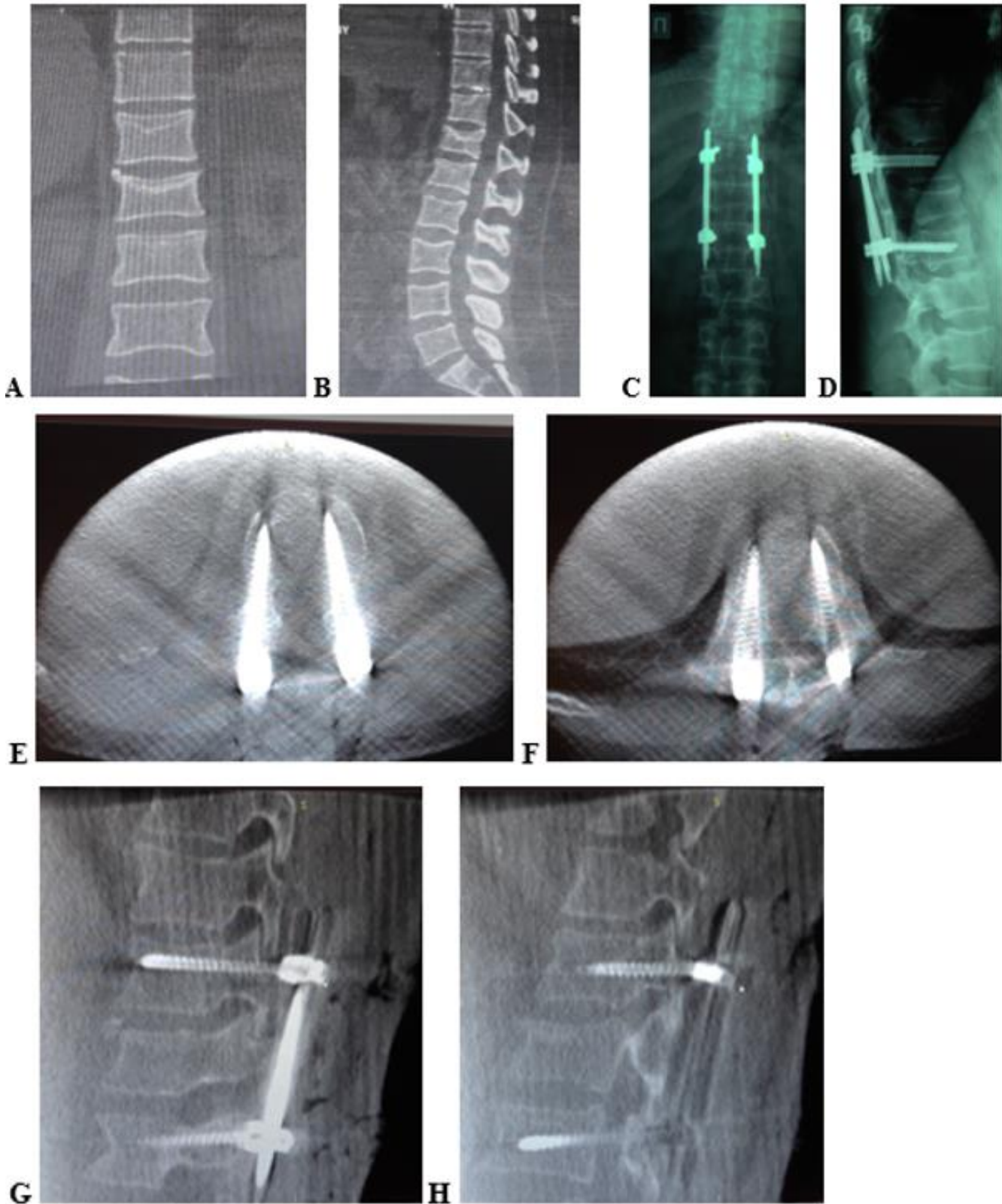

Figure 8: $A$ - frontal CT reconstruction before surgery, $B$ - sagital CT reconstruction before surgery; $C, D$ - radiographs after surgery; $O$ arm images - $E, F$ - axial images, $G$ - sagittal reconstruction on the left, $H$-sagittal reconstruction on the right

Clinical example 5. Isolated TITF. Patient A. 34 years. Diagnosis: "Multiple injury. Closed unstable uncomplicated compression fracture of the Th12 vertebral body of 1-2 degrees, stable uncomplicated compression fracture of the Th12 vertebral body, $\mathrm{L} 1$ of the vertebra of 1 degree (A2 according to $\mathrm{AO}$ ). Closed fracture of the distal metaepiphysis of the right radial bone. Condition after PQDO of the right forearm and right hand (09/22/2017), PTVF of the Th11-Th12-L1 bodies of the vertebrae with the Sixtant (Medtronic) system (09.27.2017)" (Figure 8).

Clinical example 6. TITF and PTPVBP. Patient K., 53 years old. Diagnosis: "Closed compression unstable uncomplicated fracture of the L1 vertebral body of grade 2 (A2 according to AO). Condition after TITF and PTPVBP granules of porous titanium nickelide (08.08.2018)" (Figure 9). 


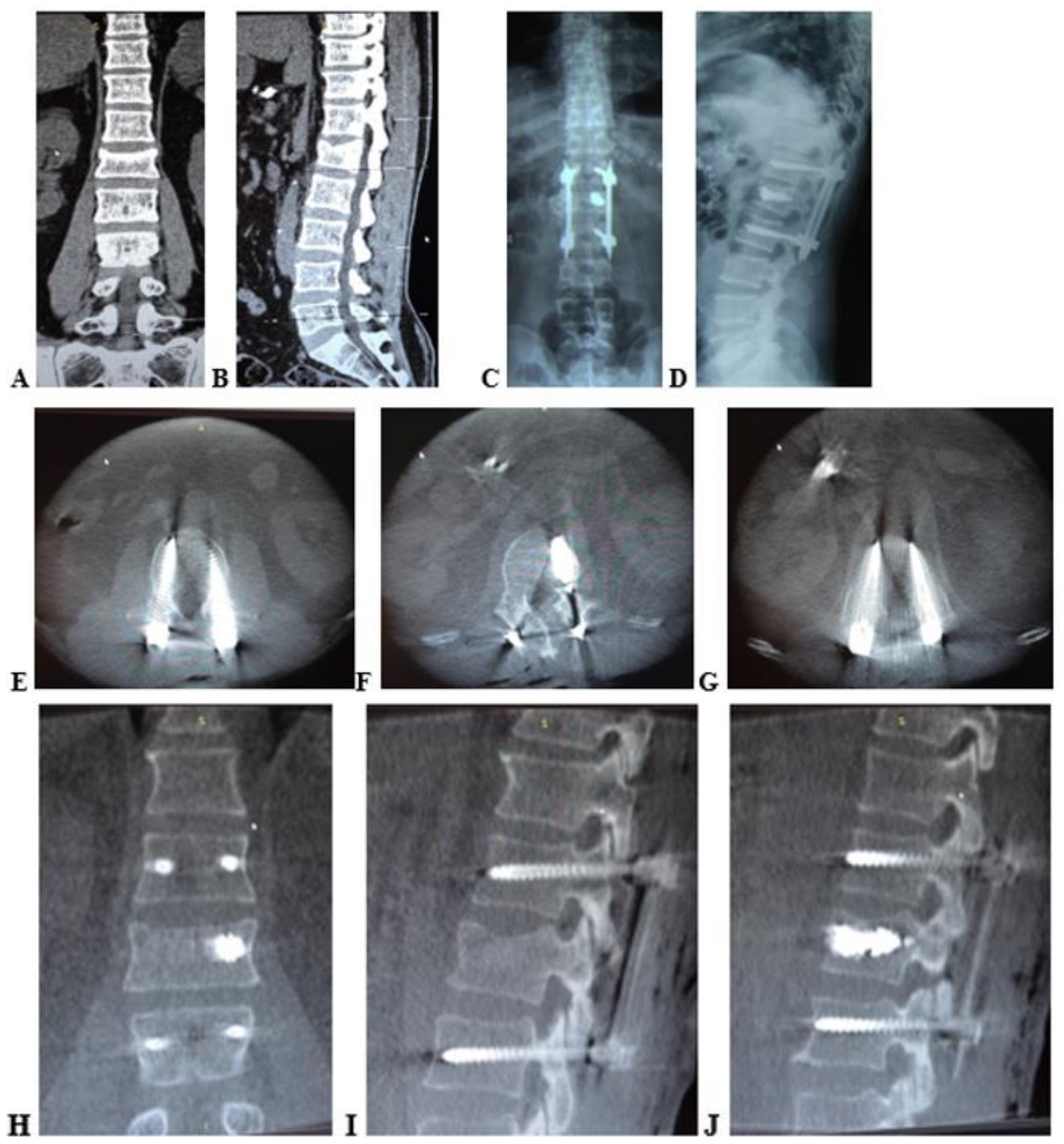

Figure 9: $A$ - frontal CT reconstruction before surgery, $B$ - sagital CT reconstruction before surgery; $O$ arm images - $E, F, G$ - axial images, $H$ - frontal reconstruction, I- sagittal reconstruction on the left, $J$ - sagital reconstruction on the right

Clinical example 7. TITF and PVP. Patient A., 68 years old. Diagnosis: "Closed uncomplicated unstable compression fracture of the Th12 vertebral body of the 2 nd to 3rd degree, the left Th12 vertebral arch (A2, B2 according to AO). Condition after TTPF by the Sixtant (Medtronic) system of the Th11-Th12-L1 vertebral bodies, PVP of the Th12 body on the right (04/18/2018)" (Figure 10).

Given the current trends in the development of surgical vertebrology in the direction of minimally invasive technologies, we can say that in combination with the navigation station, $\mathrm{O}$-arm is a powerful tool that allows minimally invasive interventions for complex fractures, deformities and diseases of the spine. 
A
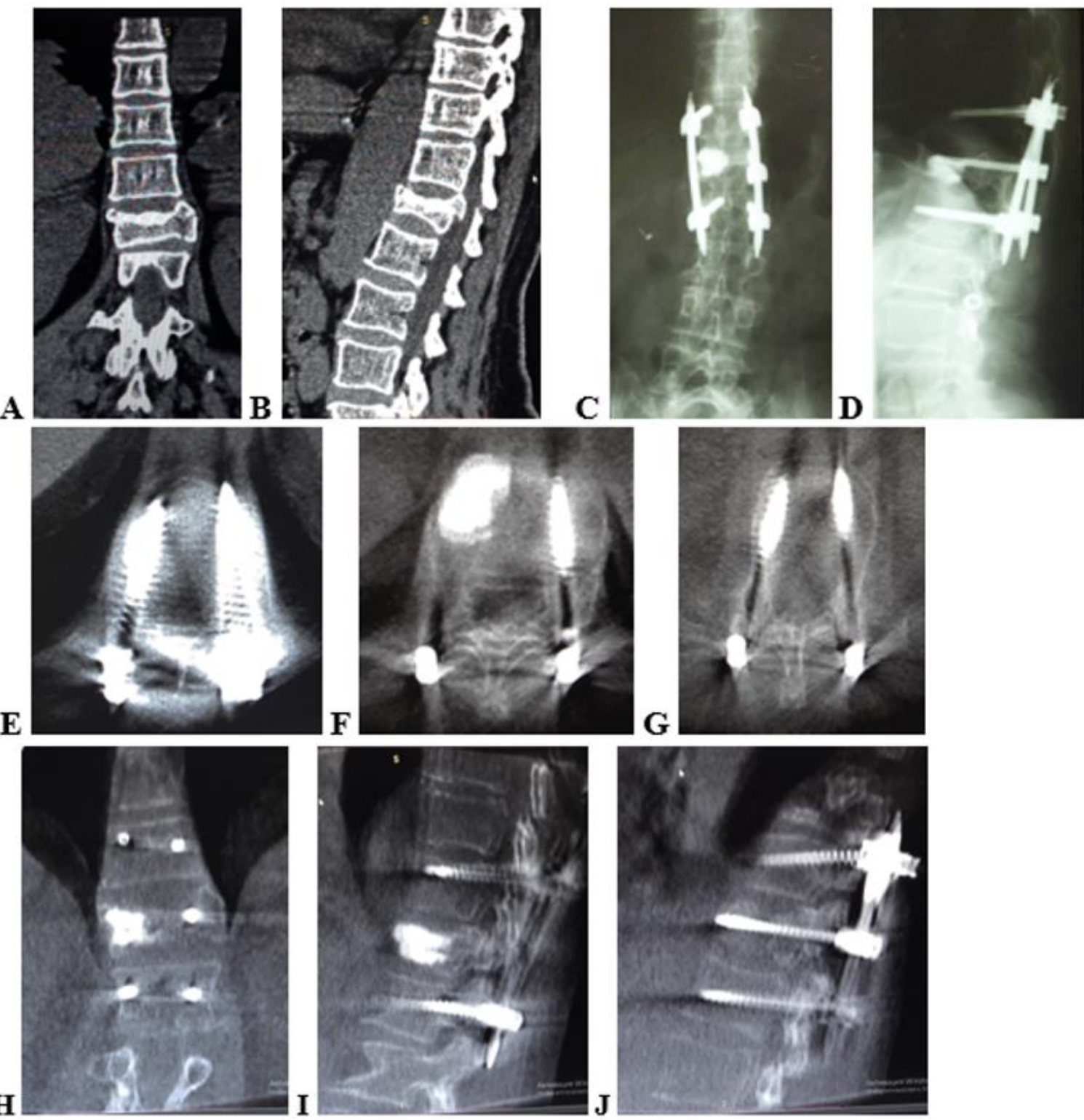

Figure 10: $A$ - frontal $C T$ reconstruction before surgery, $B$ - sagital $C T$ reconstruction before surgery; $O$ arm images - $E, F$, $G$ - axial images, $H$ - frontal reconstruction, I-sagittal reconstruction on the left, $J$-sagittal reconstruction on the right

\section{CONCLUSION}

$\mathrm{O}$-arm with the Stealth-Station navigation station is the most modern method of controlling the correctness of spinal operations when anatomical landmarks are partially invisible - with open operations or invisible at all - with minimally invasive surgical interventions in real time.

O-arm mobile intraoperative computed tomography, the use of which reduces the time of operations on the spine with guaranteed accuracy that excludes the use of revision interventions.

Henry $\mathrm{O}$-arm is simply and quickly draped with a sterile cover, ensuring sterility during the entire operation; it is easily retracted to a previously saved parking position, giving the surgeon full access to the surgical field and reduces the likelihood of errors during manual positioning.

The O-arm imaging system and the Stealth-Station navigation station help the surgeon direct the screw according to the patient's anatomical features, to bypass the hidden nerves and blood vessels and avoid damage with almost $100 \%$ accuracy and reduce the radiation dose for the surgeon and patient.

The only drawback of the O-arm with the Stealth-Station navigation station is their high cost. 


\section{REFERENCES}

1. McGraw JK, Gardella J, Barr JD, et al. J. Vasc. Interv. Radiol., 2003;14:827-31.

2. Nussbaum DA, Gailloud P, Murphy K. J. Vasc. Interv. Radiol., 2004;15(11):1185-92. https://doi.org/10.1097/01.RVI.0000144757.14780.E0 PMid:15525736

3. Fujita T, Kostuik JP, Huckel CB, et al. Complication of spinal fusion in adult patients more then 60 yeas of age. Orthopedic Clinics of Noth America, 1998;29(4):669-78. https://doi.org/10.1016/S0030-5898(05)70040-7

4. Jendrisak MD. Spontaneous abdominal aortic rupture from erosion by a lumbar spine fixation devise : a case report. Surgery, 1986;99(5):631-3.

5. Stewart JR, Barth KH, Williams GM. Ruptured lumbar artery pseudoaneyrysm: n unusual cause of retroperitoneal haemorrhage. Surgery, 1983;94:592-4.

6. Diaz $\mathrm{H}$, Lockhart $\mathrm{CH}$. Postoperative quadriplegia after spinal fusion for scoliosis with intraoperative awakening. Anest. Analg., 1987;66(10):1039-42. https://doi.org/10.1213/00000539-198710000-00027

7. Heyde CE, B Ahrm H, B Sagir H, Kaezer R. Erste Erfahrungen mit dem intraoperativen Wurzelmonitoring durch das INS-1-System an der lumbosakralen Wirbels-nule. Z Orthop. Ihre Grenzgeb., 2003;141(01):79-85. https://doi.org/10.1055/s-2003-37299 PMid:12605335

8. Deen $H G$, Birch $B D$, Wharen RE, Reimer R. Lateral mass screw corod fixation of the cervical spine a prospective clinical series with 1-year following-up. The spine journal: official journal of the North American Spine Society, 2003;3(6):489-95.

9. Daube JR. Intraoperative monitoring by evoked potentials for spinal cord surgery: the pros. Electroencephalogr. Clin. Neurophysiol., 1989;73(5):374-7. https://doi.org/10.1016/0013-4694(89)90085-0

10. Orchowski J, Bridwell KH, Lenke LG. Neurological deficit from a purely vascular etiology after unilateral vessel ligation during anterior thoracolumbar fusion of the spine. Spine, 2005;30(4). https://doi.org/10.1097/01.brs.0000153391.55608.72 PMid:15706337

11. Hamilton DK, Smith JS, Sansur CA, Glassman SD, Ames CP, Berven SH, et al. Rates of new neurological deficit associated with spine surgery based on 108419 procedures: a report of the scoliosis research society morbidity and mortality committee. Spine, 2011;36(15). https://doi.org/10.1097/BRS.0b013e3181ec5fd9 PMid:21217448

12. Sakai $Y$, Matsuyama $Y$, Nakamura $H$, et al. Segmental pedicle screwing for idiopathic scoliosis using computerassisted surgery. Journal of Spinal Disorders Techniques, 2007;21(3). https://doi.org/10.1097/BSD.0b013e318074d388 PMid:18458587

13. Rajasekaran S, Vidyadhara S, Ramesh P, Shetty AP. Randomized clinical study to compare the accuracy of navigated and non-navigated thoracic pedicle screws in deformity correction surgeries. Spine, 2007;32(2). https://doi.org/10.1097/01.brs.0000252094.64857.ab PMid:17224800

14. Han W, Gae ZL, Wang JC, et al. Pedicle screw placement in the thoracic spine a comparison study of computerassisted navigation and conventional techniques. Orthopedics, 2010;33(8). https://doi.org/10.3928/0147744720100625-14

15. Schizas $C$, Then $E$, Kwaitkowski $B$, et al. Pedicle screws insertion robotic assistance versus conventional $C$-arm fluoroscopy. Acta Orthopaedica Belgica, 2012;78(2):240-5.

16. Tian W, Liu YJ, Liu B, et al. Clinical contrast of cervical pedicle screw fixation assisted by C-arm fluoroscopy or 3D navigation system. Chinese J. Surg., 2006;44(20):1399-1402.

17. Smith HE, Welch MD, Sasso RC, et al. Comparison of radiation exposure in lumbar pedicle screw placement with fluoroscopy versus computed-assisted image guidance with intraoperative three-dimensional imaging. J. Spinal Cord Med., 2008;31(5):532-537. https://doi.org/10.1080/10790268.2008.11753648 PMid:19086710 PMCid:PMC2607125

18. Hart R, Komzak M, Barta $R$, et al. Reduction of radiation exposure by the use of fluoroscopic guidance in transpedicular instrumentation. Acta Orthopaedicae et Traumatologiae Cechoslovaca, 2011;78(5):447-50.

19. Biswas D, Bible JE, Whang PG, et al. Sterility of C-arm fluoroscopy during spinal surgery. Spine, 2008;33(17). https://doi.org/10.1097/BRS.0b013e31817bb130 PMid:18622356

20. Lapsley HM, Vogels R. Quality and cost impacts prevention of post-operative clean wound infections. Int. J. Health Care Qual Assur inc Leadersh Helth Serv., 1998;11(6-7):222-31. https://doi.org/10.1108/09526869810243935 PMid:10339096 
21. Esses SL, Sachs BL, Dreyzin V. Complications associated with technique of pedicle screw fixation. A selected survey of ABS members. Spine, 1993;18(15):2231-8. https://doi.org/10.1097/00007632-199311000-00015 PMid:8278838

22. Gautschi OP, Schatlo B, Schaller K, Tessitore E. Clinically relevant complications related to pedicle screw placement in thorac-lumbar surgery and their management a literature reviews of 35630 pedicle screws. Neurological Focus, 2011;Sep. 30-31:8. https://doi.org/10.3171/2011.7.FOCUS11168 PMid:21961871

23. Wood M, Mannion R. A comparison of CT-based navigation techniques for minimally invasive lumbar pedicle screw placement. Journal of Spinal Disorders Techniques, 2011;24(1). https://doi.org/10.1097/BSD.0b013e3181d534b8 PMid:20625324

24. Van de Kelft E, Costa F, Van der Planken D, Schils F. A prospective multicenter registry on the accuracy of pedicle screw placement in the thoracic, lumbar and sacral levels with the use of the O-arm imaging system and StealthStation navigation. Spine, 2012;37(25):1580-7. https://doi.org/10.1097/BRS.0b013e318271b1fa PMid:23196967

25. Hodges SD, Eck JC, Newton D. Analysis of CT-based navigation system for pedicle screw placement. Orthopedics, 2012;35(8):1221-4. https://doi.org/10.3928/014774447-20120725-23 PMid:22868609

26. Sembrano JN, Polly DW, Ledonio CG, Santos ER. Intraoperative 3-dimentional imaging (O-arm) for assessment of pedicle screw position. Does it unacceptable screw placement? International Journal of Spine Surgery, 2012;12(1):49-54. https://doi.org/10.1016/j.ijsp.2011.11.002 PMid:25694871 PMCid:PMC4300877

27. Schouten $R$, Lee $R$, Boyd $M$, et al. Intraoperative cone-beam $C T(O$-arm) and stereotactic navigation in acute spinal trauma surgery. Journal of clinical neuroscience: official journal of the Neurological Society of Australia, 2012;19(8):1137-43. https://doi.org/10.1016/j.jocn.2012.01.020 PMid:22721892

28. Kosmopoulos V, Schizas C. Pedicle screw placement accuracy: a meta-analysis. Spine, 2007;32(3). https://doi.org/10.1097/01.brs.0000254048.79024.8b PMid:17268254

29. Ledonio CG, Polly G, Vitale MG, et al. Pediatric pedicle screws: comparative effectiveness and safety a systematic literature review from the scoliosis research society of North America task force. The Journal of Bone Joint Surgery, 2011;93(13):1227-34. https://doi.org/10.2106/JBJS.J.00678 PMid:21776576

30. Hicks JM, Singla A, Shen FH, Arlet V. Complication of pedicle screw fixation in scoliosis surgery: a systematic review. Spine, 2010;35(11). https://doi.org/10.1097/BRS.0b013e3181d1021a PMid:20473117

31. Pourrostami $K$, Heshmat R, Hemati Z, Heidari-Beni M, Qorbani $M$, et al. Association of fruit and vegetable intake with meal skipping in children and adolescents: the CASPIAN-V study. Eating and Weight Disorders-Studies on Anorexia, Bulimia and Obesity, 2019 May 16:1-8. https://doi.org/10.1007/s40519-019-00704-w PMid:31098987

32. Jalili C, Ahmadi S, Roshankhah S, Salahshoor M. Effect of Genistein on reproductive parameter and serum nitric oxide levels in morphine-treated mice. International journal of reproductive biomedicine, 2016;14(2):95-102. https://doi.org/10.29252/ijrm.14.2.95 PMid:27200423 PMCid:PMC4869156

\author{
$\diamond \diamond \diamond \diamond \diamond \diamond \diamond$ \\ http://www.ejgm.co.uk
}

